\title{
Chapter 14 How Users Approach Discovery Tools
}

\author{
Lucy Holman \\ University of Baltimore, USA \\ Elias Darraj \\ University of Baltimore, USA \\ Jonathan Glaser \\ University of Baltimore, USA
}

\author{
Alice Hom \\ University of Baltimore, USA \\ Heather Mathieson \\ University of Baltimore, USA \\ Deane Nettles \\ University of Baltimore, USA
}

\author{
Aronya Waller \\ University of Baltimore, USA
}

\begin{abstract}
Researchers observed 21 participants (undergraduates, graduate students, and faculty) conduct known item and topic searches using EBSCO Discovery Service $(E D S)^{\mathrm{TM} l}{ }^{l}$ Ex Libris' Primo ${ }^{\mathbb{2} 2}$, and Serials Solutions ${ }^{\circledR 3}$ Summon ${ }^{\mathrm{TM}}{ }^{4}$ discovery tools to compare users' reaction to their interface design and evaluate each tool's functionality. Participants generally liked the tools' simple interfaces but had difficulty identifying material formats and faceted search features and were often confused by advanced search limiters and other features. Most demonstrated right-side blindness, failing to notice features or options on the right side of the screen. Participants expressed frustration with what they perceived as less than relevant results in many of their searches.
\end{abstract}

\section{INTRODUCTION}

Today's college students have grown up with the simple interfaces and natural language of search engines; they often turn to Google and other search engines for their academic research and

DOI: 10.4018/978-1-4666-1821-3.ch014 shy away from library tools that require more skill and expertise to use. Numerous national studies (Jones, 2002; OCLC, 2002; DeRosa, Cantrell, Hawk, \& Wilson, 2006; Head \& Eisenberg, 2009) have found that the majority of college students use search engines more than library resources for academic research. These studies point to user difficulty with navigating through library sites 
and searching library databases (OCLC, 2002). Students are often confused about which databases to use, and they are often unsuccessful at crosssearching in the databases (Stein, Bright, George, Hurlbert, Linke \& St. Clair, 2006). Users expect the simplicity of a single search box to search across sources and platforms (Stein, et al, 2006). They rarely use the advanced features in either search engines or databases, expecting the tool itself to know what they need (Williams, 1999).

Most information professionals realize that students will neither learn the more complex search strategies required by many commercial article databases nor search multiple databases to find different types of sources. Therefore, libraries face the challenge of meeting users' research needs with new search tools that have more robust algorithms and search capabilities across multiple data warehouses and formats. As more products, both commercial and open source, emerge in the marketplace, libraries must identify which tool offers both the most intuitive, user-friendly interface and the most robust search capabilities to effectively meet users' needs.

The leading discovery services offer similar features and can harvest items from subscription databases, local catalogs and digital collections. Therefore, comparisons among interfaces and general functionality are important for libraries in their decision-making. Task-based usability testing is a useful method for libraries to evaluate and compare discovery tools. Unlike other research methodologies that require large numbers of participants, usability testing can reveal common user problems with a small number of participants. Jakob Nielsen (2000, Nielsen \& Landauer, 1993), a leading researcher and practitioner in usability testing suggests that as few as five users can identify $85 \%$ of usability concerns through taskbased testing. Libraries may choose to use this methodology to study their own users in order to make an informed choice of a discovery service.

\section{LITERATURE REVIEW AND BACKGROUND}

In the mid-2000s, developers of integrated library systems and indexing and abstracting services began to create a next-generation system that would provide an alternative to the Z39.50 federated search process. Web-scale discovery harvests metadata and often full-text content from a variety of information sources, such as library catalogs, commercial databases, and local library digital repositories. This technology offers users a simple search interface and single (and, in most cases, faceted) results lists. What sets discovery services apart from federated search is in their creation of a centralized index of content across sources and platforms, which allows for a faster retrieval process (Vaughan, 2011e). Discovery tools can offer the "Google generation" an experience similar to a Google search with a broad range of academic sources. In recent years, several products, both proprietary and open-source, have emerged, including the four studied here: EBSCO Discovery Service $(E D S)^{\mathrm{TM}}$, Innovative Interface's Encore ${ }^{\mathrm{TM}}$, Ex Libris' Primo ${ }^{\circledR}$, and Serials Solutions ${ }^{\circledR}$ ' Summon ${ }^{\mathrm{TM}}$.

EDS $^{\text {TM }}$ first appeared on the general market in early 2010 (Vaughan, 2011b). EDS ${ }^{\text {TM }}$ contains content from almost 50,000 periodicals from more than 20,000 providers. It also includes metadata for almost 6 million books; 825,000 CDs and DVDs; and 20,000 conference proceedings (EBSCO Publishing, 2011). EDS ${ }^{\text {TM }}$ offers a single search box with the option for additional search features as well as an advanced search, incorporating Boolean operators and select limiters. EDS ${ }^{\mathrm{TM}}$ offers faceted navigation including limiters such as source type/format, author, publication, subject (EBSCO subject headings), and publication date; these facets dynamically present themselves based on the nature of the search. EDSTM also employs a SmartText feature that interprets strings of user input into search terms that the system runs and offers a "Did you mean?" spelling suggestions 
for misspelled terms. Results appear with visual icons representing format, citation, abstract and subject headings. EDS ${ }^{\mathrm{TM}}$ also supports an API (Application Programming Interface) that allows libraries to embed the EDS ${ }^{\mathrm{TM}}$ discovery tool in many other areas of their Web sites, such as learning management systems and research guides as well as a number of export options including saving, emailing, or exporting to citation management software and provides persistent URLs so that libraries may embed these links in their own resources (Vaughan, 2011b).

Innovative Interfaces made its Encore ${ }^{\mathrm{TM}}$ discovery tool available in 2007 (Breeding, 2007). Encore $^{\mathrm{TM}}$ employs federated search to retrieve items from a library's subscription databases; libraries can incorporate local digital content or holdings from other collections into Encore's search engine. Encore features a single search box with the option for advanced search; its facets include format, year, and language among others. Additionally, Encore offers "Did you mean?" spelling suggestions, relevancy rankings and Web 2.0 options to rate and review items (Innovative Interfaces, 2011).

Serials Solutions ${ }^{\circledR}$ ' Summon ${ }^{\mathrm{TM}}$ discovery service was released in July 2009 (Vaughan, 2011d); it currently contains more than 500 million items from more than 94,000 periodicals (Serials Solutions $\left.^{\circledR}, 2011\right)$. Summon ${ }^{\mathrm{TM}}$ provides a single search box and an advanced search option, as well as a robust API (Application Programming Interface) that allows libraries to embed such a resource tool in many other areas of the library and university Web sites. Results are ranked by relevancy and can be sorted by date as well. The tool allows for refinements by facets such as format, author, publication date, subject terms, language, and region; the categories change as appropriate to the particular search results. Summon ${ }^{\mathrm{TM}}$ also features spelling suggestions, much like Google's "Did you mean?" and supports a number of export/save options and RSS feeds and employs persistent
URLs for embedding in other library materials (Vaughan, 2011d).

Ex Libris launched its Primo ${ }^{\circledR}$ discovery service in 2007 (Vaughan, 2011c). Primo Central ${ }^{\text {TM}} 5$, Primo's ${ }^{\circledR}$ knowledge base or centralized index, contains 300 million items, including e-books and periodical articles from aggregators, publishers, and open repositories (Ex Libris, 2011; Vaughan, 2011c). Primo's ${ }^{\circledR}$ interface is customizable; libraries may select from a set of templates, design the interface, or use Ex Libris' application programming interface (API) to integrate Primo ${ }^{\circledR}$ into a local library interface. Brief results include visual icon for format, citation, and links to full text if available. Primo ${ }^{\circledR}$ offers a “Did you mean?" spelling suggestion feature; the service also supports a variety of export options and RSS feeds and offers persistent links for embedding as well as an API to embed a Primo ${ }^{\circledR}$ search box into learning management systems (Vaughan, 2011c).

Several recent articles and reports (Yang \& Wagner, 2010; Emanuel, 2011; Allison, 2010; Vaughan, 2011a) have evaluated or compared several commercial and open-source discovery tools including Encore ${ }^{\mathrm{TM}}$, VuFind, Summon ${ }^{\mathrm{TM}}$, Primo, and OCLC's WorldCat Local. Most of these, however, compare the tools in terms of the features they offer and not in terms of usability or ease of use. Vaughan (2011a), for example, evaluated EDS ${ }^{\mathrm{TM}}$, Primo, and Summon ${ }^{\mathrm{TM}}$, along with OCLC's WorldCat Local. He compared content (the aggregators and serial titles included in each index) and interface features. Emanuel (2011) did test the usability of the University of Illinois at Urbana-Champaign's (UIUC) implementation of VuFind; however, that usability was in comparison to UIUC's WebVoyage OPAC. Her study did uncover user confusion over formats, particularly multimedia materials. Yang and Wagner (2010) evaluated 47 implementations at both public and academic libraries of 20 discovery tools (seven open source and 13 commercial) against a checklist of 13 features, such as simple search, faceted navigation, spelling correction/recommendation, 
relevancy, and persistent links. Their study found that Primo offered the most features (8 of the 13 listed), followed closely by Encore (7.5) and Summon $^{\mathrm{TM}}$ (7) (Yang \& Wagner, 2010). EDS ${ }^{\mathrm{TM}}$ was not included in their research.

While these services provide a simple interface and a number of enhanced features, such as faceted navigation, automated spelling correction, relevancy ranking, and enriched content, they do presume a level of expertise or familiarity of various information resources on the part of users. They expect users to be able in distinguish between online versions of books, journal articles, reports, primary documents and other materials. Unfortunately, users do not often distinguish between such sources, considering all online material to be similar (Whitlock \& Kiel, 2011).

\section{METHODOLOGY}

The University System of Maryland and Affiliated Institutions (USMAI) is a statewide consortium comprised of 16 libraries in 13 institutions, including four-year liberal arts colleges and comprehensive universities, law schools, medical and allied health graduate schools. The consortium shares a single integrated library system and catalog and works collaboratively to purchase databases and other electronic materials. Currently, the consortium is preparing to purchase one or more discovery tools. The consortium has several established working groups, with representatives from libraries across the system, to address common issues and research new products and services in functional areas such as electronic resources, cataloging, resource sharing and user interface design to address consortial issues and research new products and services.

In the spring of 2011, the User Interface Task Group (UITG) from USMAI contracted with graduate students in the Interaction Design and Information Architecture program at the University of Baltimore to conduct task-based usability studies on four major discovery tools: EBSCO Discovery Service $(E D S)^{\mathrm{TM}}$, Encore, Primo, and Summon ${ }^{\mathrm{TM}}$. In consultation with UITG, six teams of graduate researchers developed a set of tasks of both known-item and topic searches for users to complete during the testing. The researchers recruited participants from the University of Baltimore and other University System of Maryland campuses through campus announcements, flyers and through contacts at member universities. The researchers met with 21 participants, including eight undergraduates, seven graduate students, and six faculty members as they conducted topic and known-item searches using each of the four discovery tools. The research focused on participants' general search behaviors as well as their use of and preferences for specific features in each tool. Each participant worked with two systems; the researchers distributed specific tools across user types so that the overall project had multiple comparisons of each tool. In all, ten or eleven users examined each discovery service, which exceeds standard expectations concerning the number of participants required to identify a majority of issues. Participant tasks, which were determined with the assistance of information specialists from USMAI, included searching the discovery tools for known items, such as a specific book and journal article, conducting relative narrow topical searches for particular formats and types of sources, and employing specific limiters and faceted searches to narrow results.

The observations occurred in April 2011 using the University of Baltimore's state-of-the-art usability lab. Researchers used TechSmith's Morae video and screen capture software as well as Tobii eye-tracking software to compare participants'use of the four discovery tools. The nature or volume of content made available by each of these tools was not compared; researchers selected known items that were common to all four services and did not analyze the number of items retrieved. The focus of this research was strictly on discovery layer 
functionality and the ease in which participants learned and employed the tools to search for items.

In order to conduct task based tests, the researchers acquired access to campuses currently using each of the discovery services or were given access to a trial database. Ebsco and Encore provided access to a generic trial access, while Ex Libris provided temporary access to Boston College's Primo tool, and Serials Solutions ${ }^{\circledR}$ suggested the use of Arizona State University's Summon ${ }^{\mathrm{TM}}$ search. To ensure comparable results across tools, the researchers verified that the items used in the known item search tasks were available in all four products. Certain access problems arose in the discovery services'test environments; for example, Encore required a separate search in WorldCat Local for all books. This confused many of the participants who did not see the link to WorldCat Local and assumed that no book records were available; as a result the researchers decided not to discuss Encore in this comparison of discovery systems.

\section{RESULTS}

The results of this study focused on four main properties of the tool: interface design, search, faceted search features, and the ability to save articles for future retrieval. Additional results are shared when deemed appropriate.

\section{EBSCO Discovery Service (EDS)}

\section{Interface}

Participants found the main search interface to be very intuitive and minimalist in its approach. The results page presented a numbered list of search results, with an easily identifiable icon indicating the format. Participants clearly saw items with full text PDFs. The majority of the participants immediately noticed and used the facets available on the left side of the page. When a participant clicked on an item on the search results page, the detailed record information was consistent for all participants and tasks. The interface design was uniform throughout the site, which helped reduce confusion. Participants overlooked available tools, such as Add to Folder, Print, and Email because they were located on the far right side of the page.

\section{Search}

When participants searched for known items with an exact full title, they obtained results quickly, and the desired text material appeared in the first few results. However, when a participant only used a partial title, the results were broad. Some participants were confused as they attempted to narrow down their results. Although the item was in the catalog, search terms had to be "just right" to get the results. By trying several keyword queries and selecting the keyword, title, or author radio buttons, the majority of participants were able to find the selections. Furthermore, additional search options including an advanced search and a visual search were completely ignored by the participants.

Participants search terms contained many spelling errors; however many did not yield any suggestions from the system. One participant typed "Medernism and the Harlem Renissance" while another typed "artificial intelegence" and a "Did you mean?" suggestion provided correct spelling. When the participants noticed the suggestion and clicked on the alternative search, more accurate results were presented. Yet, there were some basic searches such as "beginner Portuguese" that yielded no spelling suggestions.

A majority of participants experienced difficulty with topic searches. Generally, results were not related to the materials needed. A better term recognition algorithm and enhanced facets for other materials, such as audiovisual materials, would greatly assist users seeking those materials.

EDS $^{\text {TM }}$ uses inconsistent terminology in the tool. On the main search page, a Search Options 
link is provided. This is a basic search with builtin faceted information. The same functionality is labeled as Refine Search on the search result page. Many users confused the two labels and did not realize that neither option was in fact the advanced search. Advanced Search and Visual Search are options under search options interface but are not clearly highlighted.

\section{Faceted Search}

During testing, participants used the filtering capabilities, which are available on the left-hand side of the results page. EDS'TM facets are contextual; they vary based on the search query and the returned results. When participants made a selection using any of the facets, the entire page grayed out except for the facet window. Participants were then required to click Update once they selected their filters. Some participants expressed their annoyance about manually clicking an update button to display results.

Furthermore, many participants stated that they expected more faceted options such as language and audiovisual materials.

Once a participant made a selection in the facets, the selection made was noted on the top of the left column showing the expanders and limiters. However, none of the participants seemed to notice this visual cue. Instead of clicking the " $X$ " to remove the selections, the participants continuously re-selected the All Results check box when they intended to expand the search and selected other options as needed.

\section{Save}

Very few participants identified ways to save the information they found. While an Add to Folder button is on the right hand side main results page, few participants drew the connection between the folder button and the save functionality. Furthermore, most participants did not identify and use the multiple options to save that are available on the detailed result page. This may have been due to right-side blindness, as about one third of participants never noticed the functionality on the right side. The few that used the feature were confident that the item was added once they identified the Add to Folder functionality. However, using the Save functionality led to confusing instructions that only worked depending on the browser and version used by the participant. If used, the majority of participants were able to retrieve items added to the Save Folder.

\section{PRIMO $^{\circledR}$}

\section{Interface}

Participants found the interface clean and easy to use. Participants noted that the results page was easy to browse and distinguish, with highlighted search criteria to aid in judging relevancy. The record detail pages were consistent and kept the participant within the Primo ${ }^{\circledR}$ interface.

Participants noted confusion when they unknowingly left the discovery tool. One participant clicked on the school's logo and was taken to the library's home page, which looked different from the Primo ${ }^{\circledR}$ home page. And when three professors abandoned Primo ${ }^{\circledR}$ and entered the databases directly, the look and feel of the site changed, which confused them, and the navigation did not then make it clear to them how to return to Primo ${ }^{\circledR}$.

\section{Search}

Search functions for Primo ${ }^{\circledR}$ include a Basic Search similar to the Google search bar, an Advanced Search with limited filters for multiple content searches, publication date, material type, and language. Participants were successful with Basic Search and found it easy to narrow using both Advanced Search and Faceted Search filters. Unfortunately, the basic search terms entered by participants did not transfer to the Advanced Search page. "I would have liked it for the fields 
I had already started to have remained," one said. In tasks involving known items, participants easily found a specific book using Basic Search, although participants sometimes confused citations for books and articles, overlooking the icons indicating the difference.

Two participants found the Material Type filter in the Advanced Search options limiting, as this option only allowed them to select one content type per search and they were interested in both books and journal articles. One user said "Here what's going through my mind is, is there a way of finding in the same place, both books and articles or do I have to do two separate searches?" Some participants expressed frustration with the designated publication date ranges; they preferred to limit through faceted search for more control. One participant said, "I wanted to use Article Finder, but I would need to know the exact issue and page number, etcetera...," and abandoned that feature.

Primo ${ }^{\circledR}$ continued to provide quick searches with relevant results. Search functions included spelling/alternate suggestions ("Did you mean?") which were often helpful. Yet, one participant followed a suggested alternative with zero results, lost his original results, and had to re-enter them. Search terms were highlighted in yellow in the search results, making it easy to determine relevance. Search terms from the last search are retained until the user clears them, though switching from Basic Search to Advanced Search cleared the search terms. One feature participants were impressed with was the ability to search individual libraries and have a map show where the book was located in the stacks.

\section{Faceted Search}

Once results have been found using Basic or Advanced Search, additional Faceted Search filters are available in a bar to the left of the results to further refine the search. Most Faceted Search options are shown by default; finding the cor- rect filter often required scrolling through a long list that was difficult to scan quickly. In Faceted Search, the user can only select one filtering option at a time in each category. For example, searching for books and multimedia has to be done in two separate searches. Participants experienced in library searches began with the Advanced Search interface, where they were able to limit their searches to material from the last five years, but were unable to limit the articles to peer-reviewed from the Advanced Search options. On the results page, participants were often unable to locate the Peer-reviewed Journals filter located under the Availability heading, several headings down the page. Refining results to a custom date range through faceted search was made difficult by the seemingly arbitrary grouping of fixed dates.

\section{Save}

One undergraduate and one professor used Primo's ${ }^{\mathbb{R}}$ eShelf system to save their articles, but all but two of participants bookmarked their links using methods that did not involve Primo ${ }^{\circledR}$.

\section{SUMMON ${ }^{\mathrm{TM}}$}

\section{Interface}

The Summon ${ }^{\mathrm{TM}}$ discovery service interface consists of a single search box, an advanced search page, and a comprehensive results page with an interactive left sidebar containing faceted filtering criteria. Anchored to the bottom of the browser is a bar containing the Saved Items folder. Dynamic features to refine, save, and export results were overlooked by many participants due to their subtle integration into the layout. The results appear as an unnumbered list of items in which a record preview appears when a user hovers over an item title or clicks a magnifying glass icon. Summon ${ }^{\mathrm{TM}}$ does not offer detailed record pages for the items in the search results; instead, item titles link directly to the detailed record in the source library catalog 
or database, an interface change that caused much confusion for participants.

Participants found the graphical layout implemented by Arizona State University Libraries too subtle; elements appear flat, lacking graphical hierarchy. Participants had trouble distinguishing item titles from bold search terms. Long headings appear as a mix of bold and normal type, leading to an uneven appearance that decreases readability. In addition, headings are set far left of the item description text block, breaking the vertical flow of browsing the text.

Even with visual cues indicating content type with an icon and a text field, some participants could not discern differences between listings. When asked to find a specific translation of the book Beowulf, multiple participants indiscriminately selected the first items without noticing they were peer-reviewed articles instead of a book. At a glance, the icons appeared similar in shape and coloring, without enough variation in the graphic photo to indicate different content types. In addition, full-text items are identified with a bright yellow sunburst on top of the icon, making the shapes more similar and calling more attention to the full text than the content type.

\section{Search}

Participants usually started at the Basic Search on the library homepage. Participants were overwhelmed with the library's multiple options; one participant expressed uncertainty, asking, "where do I start?" Those who wanted more control did not find a direct link to the advanced search options on the library's main search page; instead, they tried links to the native library catalogs and databases, which were not part of the discovery tool. Many participants perceived the library's diverse resources as a single entity, which led to confusion when they encountered inconsistent interfaces between Summon ${ }^{\mathrm{TM}}$ and the search pages of other databases. The advanced search link only appears after an initial search has been conducted from the basic search box.

Often, Summon ${ }^{\mathrm{TM}}$ did not match the participants' keywords with their intended results. Many undergraduate participants entered full phrases from the prompt, which returned irrelevant results. This behavior is encouraged by popular internet search engines that incorporate algorithms to parse search terms based on natural language patterns. The basic search interface offers an auto-complete list of suggested terms, though it is not available on the library home page, where most initial search entry errors occur. "Did you mean?" misspelling corrections were relevant and helpful, but many participants did not notice them because they were not highlighted separately from the results list. The logic behind the relevancy ranking is not transparent in the list of results, and the interface does not support easy scanning of results.

\section{Faceted Search}

After an initial basic search, users are presented with a results page headed by a search box and options for advanced search. A few participants went directly to advanced search for subsequent search tasks and were successful in using the comprehensive options to complete tasks. Users transferred previously-entered search terms from the basic search to the advanced search form for convenience, which minimized entry errors that were observed when participants had to retype them. Although the search criteria were saved, the results page did not indicate which specific criteria or limiters users had employed.

Half of the participants did not engage deeply with Summon ${ }^{\mathrm{TM}}$ 's interactive multi-faceted filters. Eye- and mouse-tracking patterns indicated that participants focused mainly on the listings section when scrolling through the results and may not have noticed options such as the graphical custom date slider located further down the page. Participants who tried the facets were reassured when options remained in place even as the results 
changed. One participant said, "Oh it keeps all my things here still." However, another participant had a black screen for about a second as the results were updated to reflect facet changes and led to the comment, "Again, oh I don't like that one." Except for dates, the filtered results are updated automatically after selecting checkboxes, but the update buffering page and sometimes blackout background can be a little jarring.

\section{Save}

Very few participants clicked on the folder icon within the item record to store the record in a temporary folder; those who did were very impressed with the export options. Many preferred to bookmark links in their browser.

Table 1 summarizes users' experiences with each tool.

\section{DISCUSSION}

This research revealed some similarities in the participants' approach to search. Users - faculty, undergraduate students, and graduate students - almost instinctively began their first task by clicking on the search box and submitting their first query. This is remarkable because it demonstrates the pervasiveness of the simple search functionality. The participants across the various user groups trusted that the system would display appropriate results to their search. When users did not find the appropriate result, the similarities between and within user-groups became less evident in their advanced search approach and frustration threshold. Some users tried to anticipate what keywords the system would understand, while others tried to understand why the system did not understand their keywords. Another similarity between users was lack of knowledge of library jargon. Many users, including faculty, did not understand the Boolean search concept. Users were frustrated when they did not understand certain labels for functionality, like Boolean search. As users progressed through the tasks, several commented that they would have contacted a librarian to complete the task. Users seeking answers outside of the system is not a good indication of a tool's usability.

Table 1. Summary of discovery tool findings

\begin{tabular}{|c|c|c|c|c|}
\hline Tool & Interface & Search & Faceted Search & Save Features \\
\hline EDS & $\begin{array}{l}\text { - Users recognized format icons } \\
\text { and noticed limiting facets }\end{array}$ & $\begin{array}{l}\text { - Topic searches yielded } \\
\text { unrelated results } \\
\text { - System did not offer } \\
\text { suggestions for some } \\
\text { misspellings } \\
\text { - Users did not use advanced } \\
\text { or visual search }\end{array}$ & $\begin{array}{l}\text { - Users took advantage } \\
\text { of facets } \\
\text { - Users suggested } \\
\text { additional facets } \\
\text { - Users failed to notice } \\
\text { which facets were being } \\
\text { used }\end{array}$ & $\begin{array}{l}\text { - Users failed to } \\
\text { notice Add to } \\
\text { Folder or Email } \\
\text { options }\end{array}$ \\
\hline Primo & $\begin{array}{l}\text { - Users found interface easy } \\
\text { to use } \\
\text { - Icons and layout were } \\
\text { consistent } \\
\text { - Users were unaware when they } \\
\text { left the tool. }\end{array}$ & $\begin{array}{l}\text { - Users successful with basic } \\
\text { search } \\
\text { - Search string did not transfer } \\
\text { from basic to advanced search }\end{array}$ & $\begin{array}{l}\text { - Users found facet list } \\
\text { too long } \\
\text { - Users wanted to limit by } \\
\text { multiple facets } \\
\text { simultaneously }\end{array}$ & $\begin{array}{l}\text { - Few users saved } \\
\text { items using } \\
\text { Primo's eShelf }\end{array}$ \\
\hline Summon & $\begin{array}{l}\text { - Users failed to visual cues } \\
\text { such as format icons or } \\
\text { full-text availability }\end{array}$ & $\begin{array}{l}\text { - Users could not navigate } \\
\text { directly to advanced search } \\
\text { - Search terms yielded } \\
\text { unrelated results } \\
\text { - Some users failed to see } \\
\text { suggested spellings }\end{array}$ & $\begin{array}{l}\text { - Half of users did not } \\
\text { engage with facets } \\
\text { - Users appreciated that } \\
\text { options remained when } \\
\text { results changed }\end{array}$ & $\begin{array}{l}\text { - Few used folder } \\
\text { feature }\end{array}$ \\
\hline
\end{tabular}


Many of the tools display simple search functionality, challenging the algorithm to understand what knowledge the user is seeking. Most of the participants within the study preferred a clean, simple interface, even if it did not produce the "correct" results. However, an interface can be visually appealing and still have usability issues, as was the case with EDS ${ }^{\mathrm{TM}}$. While EDS ${ }^{\mathrm{TM}}$ is designed with a simple search interface, several participants expressed frustration due to inconsistent search results. Designers of discovery tools need to find the fine balance between simple interface design and powerful search and filtering capabilities.

The discovery tools' features confused many of the participants, particularly when the participants used the faceted search. For example, the way Primo's ${ }^{\circledR}$ filter list was displayed was so long that options at the bottom of the page were overlooked. Illogically, there were more filtering options available in the results sidebar than in the advanced search form. This may indicate the developer's expectation that users prefer to begin with a broad search, then narrow the results contextually rather than enter specific criteria through advanced search. In EDS ${ }^{\mathrm{TM}}$, the limiters change once a selection is made under the Show More link. This caused confusion among the participants. All the discovery tools still need to properly customize and test their search filters. Generally, participants succeeded in their search by starting from the simple search interface and then utilizing the advanced search functionality.

The most consistent issue among all the tools was the search for non-scholarly materials, such as textbooks and audiovisual materials. Participants appeared confused and became frustrated during this task. The inability to query based on audiovisual materials of some tools, and the user's tendencies to ignore visual cues for material type in other tools, made this task especially frustrating. Querying multiple academic databases does not prove effective in finding these materials, as the participants became inundated with scholarly articles.
Another consistent user problem throughout the tools is the inability of the user to distinguish the types of materials from the results. For example, participants often could not make a distinction between a book and an article. Additionally, problems arose with the publication name filtering capabilities within EDSTM. The publication could not be filtered by publication name, American Quarterly, only by publication type, American Literature. Those participants ultimately had to include additional words to find the correct results. While EDS ${ }^{\mathrm{TM}}$ did have search filter to search by journal name, the majority of participants did not find it.

In testing, the user groups varied in their approach to completing their search. Undergraduate students seemed more willing to reenter keywords in the simple search repeatedly, while faculty were quicker to search using the advanced search capabilities. Discovery tools must retrieve the desired results or face the risk of losing the user to either a librarian or a different search system. Overall, these tools frustrated many of the users; however, some advanced users were excited about the potential of the technology.

It appears that the producers of discovery services considered the needs of the user. They realized that users need search tools with robust algorithms and the ability to search across multiple databases. They realized that these discovery tools must be intuitive and user-friendly. Yet, those considerations were not always successful. The research here discovered that it can be difficult to create one tool that addresses the needs of multiple types of users in a clean interface. If faceted search options and limiters are provided, vendors should use a minimalist approach. Companies should consider right-side blindness and information that is put "below-the-fold." The most important features of the discovery tool should be highlighted at the top of the screen or in the left column. Providing relevant spelling corrections and suggestions within the discovery tool may 
assist a user in finding the desired information, but the suggestions need to stand out to be noticed.

\section{CONCLUSION}

The three discovery tools examined here each have certain advantages and disadvantages over their competitors. However, the greatest problem found across all tools was retrieving meaningful and relevant results from a given keyword search. This should be a major concern for all companies since these are systems designed to search. Companies can provide a robust advanced search menu system, but they must also ensure that users will have frequent success within a simple search interface. In this age of technology, users have been trained to expect quick and easy results through Google. While librarians may be looking for the most sophisticated tools with the highest standards, companies should design discovery tools that work for the lowest common denominator. Let it be noted that this level is not based on role of undergraduate, graduate, or faculty; degree program; or institution. These results have proven that there were marked issues in locating even basic types of information. A discovery tool should be designed so that users do not need to locate help or "Frequently Asked Questions" before use.

The attempt to simplify a search across multiple databases and from a variety of sources is difficult to achieve. The potential is tremendous, but the execution must be flawless. In this research, the tools did not deliver such an execution, and as a result, many participants were frustrated with the tools. In order for discovery tools to succeed, users must find the information for which they are searching on the first page of the results. In 2009, Google had over 7,000 employees working on research and development and spent $\$ 2.8$ billion dollars on Research and Development (Google, 2009). In copying the minimalistic user interface design of Google, users expect the system to operate with the same success. If the system is not perceived to work as efficiently, users will abandon the system. During this testing, many of the participants became frustrated, stating, "this is where I would go to Google" or "this is where I would go to Google Scholar;" some did abandon the systems tested. While discovery services offer library users an opportunity to quickly search multiple collections through a single interface, they still must provide more relevant results with more intuitive search features to compete successfully with search engines.

The research here yielded useful findings for libraries considering any of these discovery services and for the developers themselves; however, continued user testing is required. The producers frequently modify the interface, design and search features and should test with end-users with each modification. These results do not include Innovative Interfaces' Encore product, OCLC WorldCat Local or other open source discovery tools; further study with a wider selection of tools is warranted.

Lastly, product developers should observe user behavior in dealing with limitations in each of the discovery services. This study employed materials that researchers knew were available in all the products' knowledge bases. Unfortunately, no service fully integrates all of a library's resources; some content lives outside the tools' indexes and must be retrieved through federated search. It would be useful to examine how users respond to links outside the discovery service and then return to it; the research here observed some difficulty and confusion when users left the discovery tool and tried to return.

While discovery tools have offered libraries and their users a great service in gathering a myriad of library resources into one knowledge base with a single interface, searchers still face challenges with each of the products. In this age of Google, producers and librarians alike must continue to develop and support systems that provide robust search with simple, intuitive interfaces that serve meaningful, relevant results for simple (and of- 
ten problematic) search strings in order for us to compete with public search engines.

\section{FUTURE RESEARCH DIRECTIONS}

The research here begins a process of observing actual end users in their search of library materials using discovery tools. Much more research needs to be done to explore the ways in which students generally approach the search process, the decisions they make about where to search and what criteria to use to measure items they find and success in their information seeking. Using methodologies such as contextual inquiry or ethnographic interviews, researchers can both observe student information seeking behaviors and question students on their thought processes and decision making. Many students seemed quite unaware of when they left one particular tool and entered another (for example leaving the discovery layer and entering a library catalog or particular database) and then had difficulty navigating back to where they began. While discovery tools' interfaces may be simplistic, the list of results and number of formats may still be daunting to students of the Google generation. More research is needed to understand how students formulate search queries, the way they combine terms and phrases so that discovery tools make strengthen and fine tune their algorithms. Developers must also observe students to recognize their thought processes in distinguishing between types of content and format and evaluating resources in terms of topical relevance, academic quality and appropriateness. Secondly, continued research is required to identify user frustrations in the discovery tools themselves. Studies must identify underutilized or undiscovered features and confusing labels or directions. Designers need to establish which facets users expect and they combinations and interaction of facets or limiters they most desire. As they recognize common behaviors and mistakes developers can build more effective discovery services that can provide relevant, useful materials for the most novice of users.

\section{REFERENCES}

Allison, D. (2010). Information portals: The next generation catalog. Journal of Web Librarianship, 4(4), 375-389. doi:10.1080/19322909.20 10.507972

Breeding, M. (2007). Encore. Library Technology Reports, 43(4), 23-27.

DeRosa, C., Cantrell, J., Hawk, J., \& Wilson, A. (2006). College students'perceptions of libraries and information resources: A report to the OCLC membership. Dublin, OH: OCLC. Retrieved from http://www.oclc.org/reports/pdfs/studentperceptions.pdf

EBSCO Publishing. (2011). EBSCO discovery service content. Retrieved June 17, 2011, from http://www.ebscohost.com/discovery/eds-content Emanuel, J. (2011). Usability of the VuFind nextgeneration online catalog. Information Technologies and Libraries, 30(1), 44-52.

Ex Libris. (2011). Primo Central Index: An upgraded search experience. Retrieved June 18, 2011, from http://www.exlibrisgroup.com/ category/PrimoCentral

Google. (2009). Google Form 10-K. Retrieved June 18, 2011, from http://investor.google.com/ documents/2009_google_annual_report.html

Head, A. J., \& Eisenberg, M. B. (2009). Finding context: What today's college students say about conducting research in the digital age. Project Information Literacy Progress Report, Information School. University of Washington. Retrieved from http://projectinfolit.org/pdfs/PIL_ProgressReport_2_2009.pdf 
Innovative Interfaces. (2011). Encore products: Encore discovery. Retrieved November 11, 2011, from http://encoreforlibraries.com/products/\#ed Jones, S. (2002). The Internet goes to college: How students are living in the future with today's technology. Washington, DC: Pew Internet and American Life Project. Retrieved from http:// www.pewinternet.org/pdfs/PIP_College_Report. pdf

Nielsen, J. (2000). Why you only need to test with five users. Retrieved November 11, 2011, from http://www.useit.com/alertbox/20000319.html

Nielsen, J., \& Landauer, T. K. (1993). Amathematical model of the finding of usability problems. Proceedings of INTERCHI 1993. New York, NY: ACM Press.

Online Computer Library Center. (2002). OCLC white paper on the information habits of college students: How academic librarians can influence students' web-based information choices. Retrieved from http://www.aect.org/publications/ whitepapers/2010/informationhabits.pdf

Serials Solutions. (2011). Summon content and coverage. Retrieved June 17, 2011, from http:// www.serialsolutions.com/summon-content-andcoverage

Stein, J., Bright, A., George, C., Hurlbert, T., Linke, E., \& St. Clair, G. (2006). In their own words: A preliminary report on the value of the Internet and library in graduate student research. Performance Measurement and Metrics, 7(2), 117-115. doi:10.1108/14678040610679506

Vaughan, J. (2011a). Differentiators and a final note. Library Technology Reports, 47(1), 48-53.

Vaughan, J. (2011b). Ebsco Discovery Services. Library Technology Reports, 47(1), 30-38.

Vaughan, J. (2011c). Ex Libris Primo Central. Library Technology Reports, 47(1), 39-47.
Vaughan, J. (2011d). Serials Solutions Summon. Library Technology Reports, 47(1), 22-29.

Vaughan, J. (2011e). Web scale discovery: What and why? Library Technology Reports, 47(1), $5-11,21$.

Whitlock, B., \& Kiel, S. (2011). What I learned from teaching a for-credit information literacy class. Presentation at the Maryland Library Association Annual Conference, May 6, 2011.

Williams, P. (1999). The Net generation: The experiences, attitudes and behavior of children using the Internet for their own purposes. Aslib Proceedings, 51(9), 315-322. doi:10.1108/ EUM0000000006991

Yang, S. Q., \& Wagner, K. (2010). Evaluating and comparing discovery tools: How close are we towards next generation catalog? Library Hi Tech, 28(4),690-709. doi:10.1108/07378831011096312

\section{ADDITIONAL READING}

Alshamari, M., \& Mayhew, P. (2009). Technical review: Current issues of usability testing. IETE Technical Review, 26(6), 402-406. doi:10.4103/0256-4602.57825

Anandhan, A., Dhandapani, S., Reza, H., \& Namasivayam, K. (2006). Web usability testing: CARE methodology. Proceedings of the Third International Conference on Information Technology, New Generations. Los Alamitos, CA: IEEE Computer Society

Barnum, C. (2002). Usabilitytesting and research. New York, NY: Longman.

Becher, M., \& Schmidt, K. (2011). Taking discovery systems for a test drive. Journal of Web Librarianship, 5(3), 199-219. doi:10.1080/1932 2909.2011.583134 
Christian Bastien, J. M. (2010). Usability testing: A review of some methodological and technical aspects of the method. International Journal of Medical Informatics, 79(4). doi:doi:10.1016/j. ijmedinf.2008.12.004

Connaway, L. S., \& Dickey, T. J. (2010). Towards a profile of the researcher of today: What can we learn from JISC Projects? Common themes identified in an analysis of JISC virtual environment and digital repository projects. Retrieved from http://ie-repository.jisc.ac.uk/418/2/VirtualScholar_themesFromProjects_revised.pdf

Connaway, L. S., Dickey, T. J., \& Radford, M. L. (2011). "If it is too inconvenient I'm not going after it:" Convenience as a critical factor in information-seeking behaviors. Library \& Information Science Research, 33(3), 179-190. doi:10.1016/j.lisr.2010.12.002

Denton, W., \& Coysh, S. J.(2011). Usability testing of VuFind at an academic library. Library Hi Tech, 29(2),301-319. doi:10.1108/07378831111138189

Dixon, L., Duncan, C., Fagan, J. C., Mandernach, M., \& Warlick, S. E. (2010). Finding articles and journals via Google Scholar, journal portals, and link resolvers: Usability study results. Reference and User Services Quarterly, 50(2), 170-181.

Duchowski, A. (2007). Eye tracking methodology: Theory and practice (2nd ed.). London, UK: Springer.

Gross, J., \& Sheridan, L. (2011). Webscale discovery: The user experience. New Library World, 112(5/6), 236-247. doi:10.1108/03074801111136275

Hackos, J. T., \& Redish, J. C. (1998). User and task analysis for interface design. New York, NY: Wiley.
Hornbæk, K. (2010). Dogmas in the assessment of usability evaluation methods. Behaviour \& Information Technology, 29(1), 97-111. doi:10.1080/01449290801939400

James, D., Garrett, M., \& Krevit, L. (2009). Discovering discovery tools: Evaluating vendors and implementing Web 2.0 environments. Library Hi Tech, 27(2), 268-276. doi:10.1108/07378830910968218

Jones, R., Milic-Frayling, N., Rodden, K., \& Blackwell, A. (2007). Contextual method for the redesign of existing software products. International Journal of Human-Computer Interaction, 22(1/2), 81-101.

Kuniavsky, M. (2003). Observing the user experience: A practitioner's guide to user research. San Francisco, CA: Morgan Kaufmann Publishers.

Lazar, J., Feng, J. H., \& Hochheiser, H. (2010). Researchmethods in human-computer interaction. Chichester, UK: Wiley.

Leventhal, L. (2008). Usability engineering: Process, products, and examples. Upper Saddle River, NJ: Pearson/Prentice Hall.

Lindgaard, G., \& Chattratichart, J. (2007). Usabilitytesting: what have we overlooked? Proceedings of the SIGCHI Conference on Human Factors in Computing Systems. New York, NY: ACM Press.

Luther, J. J., \& Kelly, M. C. (2011). The next generation of discovery. Library Journal, 136(5), 66-71.

Nielsen, J., \& Pernice, K. (2010). Eyetracking web usability. Berkeley, CA: New Riders.

Prasse, M. J., \& Connaway, L. S. (2008). Usability testing: Method and research . In Radford, M. L., $\&$ Snelson, P. (Eds.), Academic library research: Perspectives and current trends (pp. 214-252). Chicago, IL: Association of College and Research Libraries. 
Prescott, L., \& Erway, R. (2011). Single search: The quest for the Holy Grail. Dublin, OH: OCLC Research. Retrieved from http://www.oclc.org/ research/publications/library/2011/2011-17.pdf

Rubin, J. (2008). Handbook of usability testing: How to plan, design, and conduct effective tests (2nd ed.). Indianapolis, IN: Wiley.

U.S. Department of Health and Human Services. (2011). Usability.gov. Retrieved from http://www. usability.gov/

Vaughan, J. (2011). Web scale discovery services. Chicago, IL: ALA TechSource.

Williams, S. C., \& Foster, A. K. (2011). Promise fulfilled? An EBSCO Discovery Service usability study. Journal of Web Librarianship, 5(3), 179-198. doi:10.1080/19322909.2011.597590

\section{KEY TERMS AND DEFINITIONS}

Application Programming Interface(API): A standard set of rules and tools used to build new programs or facilitate communication between programs. They can be considered building blocks developing new applications.

Below-the-Fold: Content on a Web site that requires scrolling in order to view it.

Eye-Tracking: A method of recording user eye movements and focal attention while he/she is viewing particular screen in order to identify areas of the screen the user views quickly and where focal attention lingers. These recorded saccadic movements and focal attention can be evaluated and compared to users' information processing to inform Web site visual design and usability.

Eye-Tracking Software: Computer program that monitors and records eye movements and creates images (see heat map) illustrating user visual paths and areas of the screen where users' focal attention concentrates.

Faceted Navigation: Movement on and through a Web site through the use of topical or format categories and subcategories

Graphical Hierarchy: A visual representation of hierarchical structure, offering a clear explanation of relative importance, size or differentiation.

Heat Map: Avisual representation of the areas of a screen where a user's gaze is fixated.

Interface: The means through which a user interacts with a computer application/program. The interface includes a means by which a user offers input and a display of the application's response.

Interface Design: The development and implementation of an application's interface with a focus on the user's needs and desires. Many interface designs strive for simplicity and intuitiveness for ease of use.

Mouse-Tracking: A method of recording computer mouse cursor movements and clicks to determine user paths and patterns of mouse behaviors.

Right-Side Blindness (sometimes known as "Ad" Blindness): The inability to see items or features on the right side of a Web site; researchers find that users have unconsciously trained themselves not to look at areas of Web sites where advertisements are generally placed.

Task-Based Usability Study: Amethodology whereby study participants are given a set of tasks to complete. Researchers measure rate and time of task completion and observe users' approaches to completing the tasks as well as observe users' reactions to the task. This method is typically preferable to interviewing users about their experiences with a particular interface; researchers can see what users actually do as opposed to what they think they would do or remember what they did. 


\section{ENDNOTES}

1 EBSCO Discovery Service is owned by EBSCO Publishing Industries

2 Primo is a registered trademark of Ex Libris Ltd. or its affiliates
3 Serials Solution is a registered trademark of Serials Solutions

Summons is owned by ProQuest LLC

Primo Central is owned by Ex Libris Ltd. or its affiliates 